\title{
Gardens for seniors. A case study in nursing Homes in Milan (Italy)
}

\author{
N. Fumagalli¹, G. Senes ${ }^{1}$, C. Ferrara ${ }^{1}$, A. Giornelli ${ }^{1}$, S. Rodiek ${ }^{2}$ and E. Bardenhagen ${ }^{3}$
}

1Department of Agricultural and Environmental Sciences, University of Milan, Milan, Italy; ${ }^{2}$ Department of Architecture, Center for Health Systems \& Design, Texas A\&M University, College Station, USA; ${ }^{3}$ Department of Landscape Architecture \& Urban Planning, Center for Health Systems \& Design, Texas A\&M University, College Station, USA.

\begin{abstract}
The health-related benefits of accessing green areas (reducing stress levels, supporting physical activity, improving mood and quality of life) are particularly important for older adults, especially in long-term care settings. Well-designed outdoors environments can encourage older adults to spend more time outside. In this context, the authors conducted a research on 60 Nursing Homes in the Milan area in order to collect information on size, conditions and quality of green spaces, using the Seniors' Outdoor Survey (SOS-2), an instrument specifically designed to assess the ability of a green area to fit the needs of seniors and guarantee accessibility and usability for them. SOS-2 has 50 items grouped in $\mathbf{5}$ domains (lush garden setting, safe and comfortable, outdoor walking and activities, easy to see and reach, connect to the world). The average size of the gardens is $3160 \mathrm{~m}^{2}$ with $60 \%$ of the structures in the range 1000-3000 $\mathrm{m}^{2}$. The garden area per bed has an average of $28.8 \mathrm{~m}^{2}$ with over $80 \%$ of the structures with more than $9 \mathrm{~m}^{2}$ of garden per bed. The SOS-2 tool uses a scale ranging from 1 (minimum) to 7 (maximum). The registered average score of the gardens is 3.29 , with about $70 \%$ of gardens with an average score of less than 3.5 . Despite the good supply of outdoor spaces nursing homes need a future increase in their quality. Research can contribute to growing the awareness that is necessary to adequately design the gardens in order to obtain the desired benefits.
\end{abstract}

Keywords: healing gardens, evaluation, access to nature, elderly, SOS-2

\section{INTRODUCTION}

The benefits of gardens on human well-being and health are wide. Green spaces can have direct benefits on individuals' health, restoring mental fatigue (Kaplan 1995; Kaplan, 2001) and reducing stress levels (Ulrich, 1984; Ulrich et al., 1991; Van Den Berg and Custers, 2011; Adevi and Lieberg, 2012), and indirect ones, stimulating and supporting social interaction and physical activity (Maas et al., 2009), increasing autonomy, improving mood (Rodiek, 2002) and quality of life (Grahn and Stigsdotter, 2003).

The health-related benefits of accessing green areas are particularly important for older adults, especially in long-term care settings where residents pass the last years of their life. Spending time in the garden can improve mood, sleeping patterns, Vitamin D absorption, and may reduce falls and fractures (Rodiek et al., 2014). It; can also help to have better sleeping patterns, less pain, decreased urinary incontinence and verbal agitation, better recovery from disability, and even increased longevity (Connell et al., 2007; Jacobs et al., 2008; Rodiek \& Lee, 2009).

Well-designed outdoors environments can encourage older adults to spend more time outdoors (Senes and Toccolini, 2013): although outdoor usage is influenced by several aspects, such as weather, health conditions, lack of interest and staff attitudes, it is also strongly related to the characteristics of the physical environment (Sugiyama \& Ward Thompson, 2007; Senes et al., 2012, Rodiek et al., 2016).

In this framework, the authors have conducted a study of green spaces included in the 60 Nursing Homes in the Milan area, in order to collect information on size, conditions and
Commentato [VIL1]: run-on sentence that is difficult to follow and may not even be complete, Rephrase and maybe break into 2 sentences. 
quality of green spaces of the structures, using the Seniors' Outdoor Survey (SOS-2) tool (Rodiek et al., 2016).

\section{MATERIALS AND METHODS}

SOS-2 is an environmental audit tool for evaluating how well the outdoor space in a long-term care setting supports the preferences and outdoor usage of residents, assessing physical environments from the user's perspective (Rodiek et al., 2016).

The instrument consists in 55 items, 5 general and 50 about specific characteristics of outdoor spaces and classified in 5 domains:

1) Lush garden setting, 8 items about the composition and quality of greenery;

2) Safe and comfortable, 18 items about outdoor comfort and safety (flooring, chairs, choice, comfort, privacy, quiet, microclimate);

3) Outdoor walking and activities, 8 items about walking and outdoor activities;

4) Easy to see and reach, 9 item about indoor-outdoor connection;

5) Connect to the world, 7 items about the possibility that the characteristics of the garden offer to establish and perceive a relationship with the outside world.

The score ranging for each question is from 1 (minimum) to 7 (maximum). Average score is considered at 4 . The survey was conducted in May and June, in order to evaluate the gardens in the period of blooming and avoiding extreme weather conditions, by 2 raters. The reliability of assigned rating was very high (average Cronbach's Alpha value 0.98, minimum 0.95).

SOS-2 was applied to the green areas of the 60 nursing homes of the District of the Local Health Authority of Milano ("ASL Milano"), located in Milan (50 of the 60) and in other six near municipalities. Each garden has been surveyed and physical data have been collected, producing detailed maps with the vegetation localization and classification.

\section{RESULTS AND DISCUSSION}

SOS 2 was applied to the areas of the 60 nursing homes of the District of the

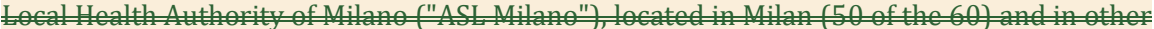
The average size of the gardens is $3160 \mathrm{~m}^{2}\left(66-16000 \mathrm{~m}^{2}\right)$, with $60 \%$ of nursing homes having 1000-6000 $\mathrm{m}^{2}$. The garden area per bed has an average of $28.8 \mathrm{~m}^{2}$ $\left(0.76-350 \mathrm{~m}^{2}\right)$, with over $80 \%$ of nursing homes having more than $9 \mathrm{~m}^{2}$ of garden per bed.

The good situation from a quantitative point of view is balanced by a not so good qualitative level of the gardens: the SOS-2 total score goes from a minimum of 1.64 to a maximum of 4.37, with a global average score of 3.29. The distribution represents about $70 \%$ of gardens with an average score of less than 3.5 (Figure 1 ).

None of the domains assessed by the tool reached the threshold average score of 4 : the situation registered goes from a minimum score of 2.66 (Connect to the world) to a maximum of 3.76 (Easy to see and reach), with a global average score of 3.15 (Table 1).

The variability and the differences among the facilities assessed are very high: the difference between the total average of the best and worst garden is equal to 2.88 points, with only 6 gardens with a total score greater than 4 and the $90 \%$ of the gardens in the range between 3 and 4 .

Table 1. Statistics of the 5 domains of the SOS-2 ${ }^{1}$

\begin{tabular}{lcccccc}
\hline Domain & Average & St. Dev. & Mode & Median & Max & Min \\
\hline Lush garden setting & 2.79 & 1.71 & 1 & 2.5 & 7 & 1 \\
Safe and comfortable & 3.28 & 1.76 & 1 & 3.5 & 7 & 1 \\
Outdoor walking and activities & 2.82 & 1.75 & 1 & 2.5 & 7 & 1 \\
Easy to see and reach & 3.77 & 1.88 & 1 & 4.0 & 7 & 1 \\
Connect to the world & 2.66 & 2.04 & 1 & 2.0 & 7 & 1
\end{tabular}

${ }^{1}$ The score ranges for each question from 1 (minimum) to 7 (maximum).

Commentato [VIL2]: Move to Methods and mention that physical data on the gardens was collected there also. 


\section{Lush garden setting}

The first domain, concerning the abundance of greening, flowers and color, the presence of reachable plants, water and wildlife and pets, got an average score of 2.79 , with over $85 \%$ of nursing homes with less than 3.5. The gardens have a fair amount of plants but with a little variety of colors and/or odors, few species, not easily touchable. There is no possibility to interact with water (fountains, ponds, lakes, etc.) and with animals.

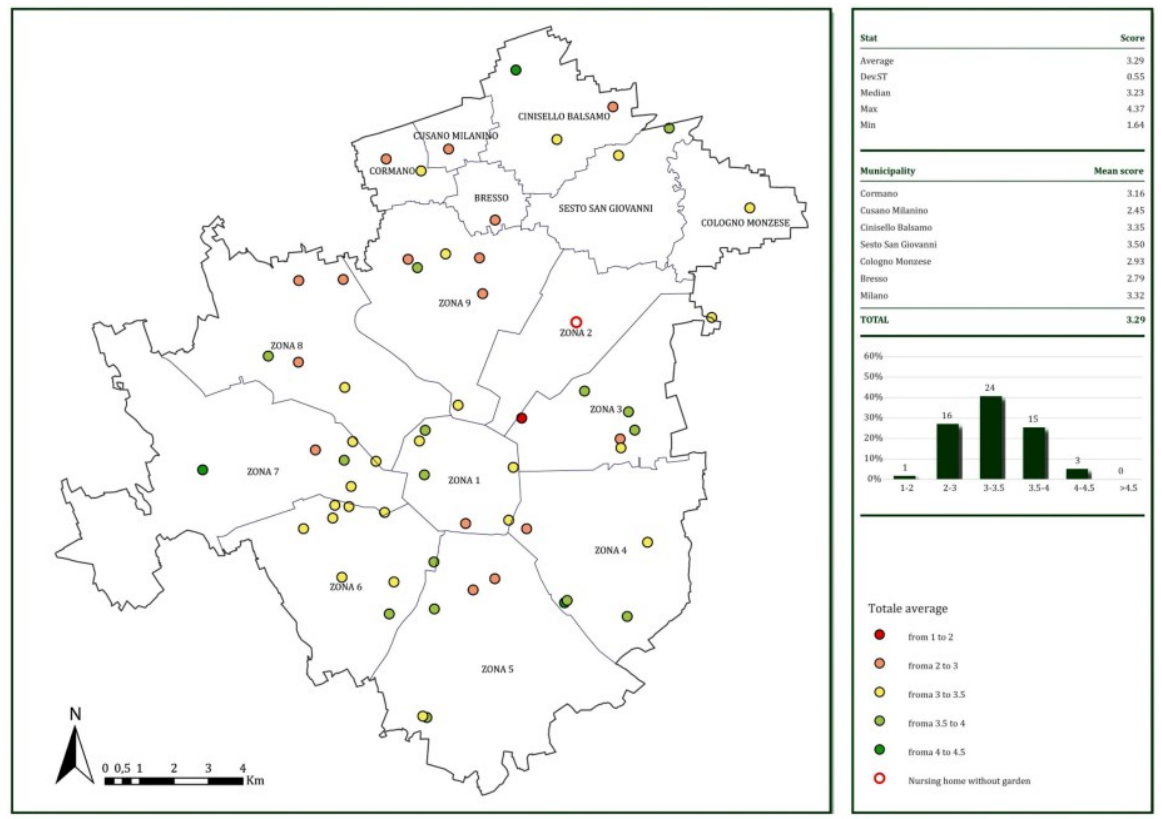

Figure 1. Overall score assigned to the gardens of the nursing homes of the study area.

\section{Safe and comfortable}

The second domain, regarding safety and comfort, obtained an average score of 3.28. Paving is generally safe, the seats are stable and quite comfortable, but don't have cushions. They are poorly distributed between sun and shade, and there are not many tables next to them. Overall, the gardens are fairly quiet, but with little sense of privacy.

\section{Outdoor walking and activities}

The third domain, regarding the characteristics of the outdoor walkways, the presence of interesting features able to attract the residents outdoors and stimulate outdoor activities, obtained a very low average score (2.82). There are not looping paths with different lengths; the walkways are not sufficiently shaded and along them there are not interesting views; seating along walkways are not well distributed. There are not interesting features the residents can enjoy or walk toward, and neither are there organized specific activities outside.

\section{Easy to see and reach}

The fourth domain, regarding visibility and physical reachability of the outdoor areas, presented a fair average score of 3.77. The gardens are often visible and easy to reach from the commonly-used sitting areas. The doors that access the garden are easy to open and the 
thresholds are easy to cross.

\section{Connect to the world}

The fifth domain, regarding the possibility to see what happens outside the facility, presented a low average score of 2.67. The gardens are usually located far from the main entry of the building, so that residents can hardly watch people arriving at the facility. There are not amenities for children. The view of nearby landscape features, streets and traffic or human activities is very poor.

\section{CONCLUSION}

This first application to ASL-Milano shows clearly the great potential of nursing homes gardens in an urban area as that of Milan. The good supply of outdoor spaces allows to trust in a next increase in quality, There is a good availability of outdoor spaces, even if the quality is generally low. This situation shows the need to raisebut it must be faced with the awareness that is necessary to adequately design the gardens in order to obtain the desired benefits, concentrating in improving the more urgent situations, as highlighted by the present research.

This study is the first in Italy and represent a sort of prototype to the analysis and evaluation of healing gardens, in view of their most appropriate design.

\section{ACKNOWLEDGEMENTS}

The authors thank the Local Health Authority “ASL Milano” for the collaboration.

\section{Literature cited}

Adevi, A.A., and Lieberg, M. (2012). Stress rehabilitation through garden therapy. A caregiver perspective on factors considered most essential to the recovery process. Urban Forestry \& Urban Greening 11, 51-58 http://dx.doi.org/10.1016/j.ufug.2011.09.007.

Connell, B.R., Sanford, J.A., and Lewis, D. (2007). Therapeutic Effects of an Outdoor Activity Program on Nursing Home Residents with Dementia. Journal of Housing for the Elderly, 21 (3/4), 195-209 http://dx.doi.org/10.1300/J081v21n03_10.

Grahn, P., and Stigsdotter, U.A. (2003). Landscape planning and stress. Urban Forestry \& Urban Greening, 2 (1), 1-18 http://dx.doi.org/10.1078/1618-8667-00019.

Jacobs, J.M., Cohen, A., Hammerman-Rozenberg, R., Azoulay, D., Maaravi, Y., and Stessman, J. (2008). Going outdoors daily predicts long-term functional and health benefits among ambulatory older people. J Aging Health, 20 (3), 259-72 http://dx.doi.org/10.1177/0898264308315427.

Kaplan, S. (1995). The restorative benefits of nature: Toward an integrative framework. Journal of Environmental Psychology, 15, 169-182 http://dx.doi.org/10.1016/0272-4944(95)90001-2.

Kaplan, S. (2001). Meditation, restoration and the management of mental fatigue. Environment and Behavior, 33 (4), 480-506 http://dx.doi.org/10.1177/00139160121973106

Maas, J., Van Dillen, S.M.E., Verheij, R.A., and Groenewegen, P.P. (2009). Social contacts as a possible mechanism behind the relation between green space and health. Health Place, 15.(2), 586-595 http://dx.doi.org/10.1016/j.healthplace.2008.09.006.

Rodiek, S. (2002). Influence of an Outdoor Garden on Mood and Stress in Older Persons. Journal of Therapeutic Horticulture, 13, 13-21.

Rodiek, S., and Lee, C. (2009). External space: Increasing outdoor usage in residential facilities for older adults. World Health Design, 2 (4), 49-55. Retrieved from www.worldhealthdesign.com.

Commentato [VIL5]: This phrase does not make sense. I can't tell what it means 
Rodiek, S., Lee, C., and Nejati, A. (2014). You Can't Get There From Here: Reaching the Outdoors in Senior Housing. Journal of Housing For the Elderly, 28 (1), 63-84 http://dx.doi.org/10.1080/02763893.2013.858093. Rodiek, S., Nejati, A., Bardenhagen, E., Lee, C., and Senes, G. (2016). The Seniors' Outdoor Survey: An Observational Tool for Assessing Outdoor Environments at Long-Term Care Settings. The Gerontologist, 56 (2), 222-233 http://dx.doi.org/10.1093/geront/gnu050.

Senes G., and Toccolini, A. (2013). Healing Gardens: le aree verdi per il benessere dell'uomo. In Rinverdiamo la città. Parchi, orti e giardini, M.A. Breda, and M.C. Zerbi, eds. (Torino, Italy: Giappichelli), p. 65-88.

Senes, G., Fumagalli, F., Crippa, R., and Bolchini, F. (2012). Nursing Homes: Engaging Patients and Staff in Healing Garden Design through Focus Group Interviews. Neuropsychological Trends, 12, 135-146 http://dx.doi.org/10.7358/neur-2012-012-sene.

Sugiyama, T., and Ward Thompson, C. (2007). Outdoor environments, activity and the well-being of older people: Conceptualising environmental support. Environment and Planning A, 39, 1943-1960 http://dx.doi.org/10.1068/a38226

Ulrich, R.S. (1984). View through a window may influence recovery from surgery. Science, 224 (4647), 420-421 http://dx.doi.org/10.1126/science.6143402.

Ulrich, R.S., Simons, R.F., Losito, B.D., Fiorito, E., Miles, M.A., and Zelson, M. (1991). Stress recovery during exposure to natural and urban environments. Journal of Environmental Psychology, 11, 201-230 http://dx.doi.org/10.1016/S0272-4944(05)80184-7.

Van Den Berg, A.E., and Custers, M.H.G. (2011). Gardening Promotes Neuroendocrine and Affective Restoration from Stress. Journal of Health Psychology, 16 (1), pp 3-11 http://dx.doi.org/0.1177/1359105310365577. 